INTERNATIONAL DESIGN CONFERENCE - DESIGN 2018

https://doi.org/10.21278/idc.2018.0350

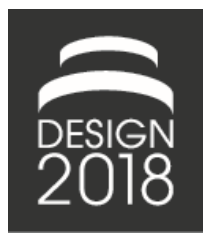

\title{
LIVING LABS AS A METHODOLOGY FOR SERVICE DESIGN - AN ANALYSIS BASED ON CASES AND DISCUSSIONS FROM A SYSTEMS APPROACH VIEWPOINT
}

\author{
M. Yasuoka, F. Akasaka, A. Kimura and M. Ihara
}

\begin{abstract}
Recently "Living Labs (LLs)" have attracted attentions as a method which aims at actively involving citizens for longer term to co-create service. Despite its increased interests, there is no unified definition of what LLs are. In order to develop a service successfully by utilizing this approach, it is of critical importance to understand the methodology in depth, and then localize them to fit to conditions in practice. In this paper, we investigated preceding LL cases in Japan and Scandinavia, depict the methodological features of LL, and review them from the systems approach perspective.
\end{abstract}

Keywords: co-design, participatory design, design methodology, design process

\section{Introduction}

Living lab approaches have recently attracted attention as a community service design method (e.g. Kareborn and Stahlbrost (2009), Binder et al. (2011), Almirall et al. (2012) and EC ENoLL (2015)). Living labs aim at actively involving citizens and other stakeholders for a long-term period (Ogonowski, 2013). The objective is to co-create and prototype services from ideas, and test them in the real-life environment of the end-users. By utilizing this living labs approach, it is possible to embody the value of co-created ideas and concepts into services, when they enroll in society. Practices on societal challenges and regional social innovation have primarily been reported from Scandinavian countries and North America, but Asian applications of living labs also exit (Yasuoka and Kamihira, 2016). Currently, there is no unified definition of what living labs are. The word is used in many different contexts, processes, and meanings. The practice is carried out by a few skilled practitioners and the methodology has not been systematically organized yet (Schuurman et al., 2015). Under these circumstances, it is not an easy task to apply the method to other socio-technical and socio-cultural settings without having an in-depth understanding of the nature of living labs. In order to develop a service successfully by utilizing living lab approaches, it is important to understand the methodology in depth, and then localise the approach to fit it to a new social environment.

Our ultimate goal is to localize living lab approaches to socio-culturally environments outside Scandinavia and North America. To that end, in this research, we aim to clarify the characteristics of living lab as a service design methodology. More specifically, we will clarify the following two research questions:

1. How can we conduct service design in living lab environment?

2. What are essential differences between living lab approach and traditional service design approach (e.g. Stickdorn and Schneider (2012))? 
This paper first reviews literature of previous studies on living labs and depicts the critical features of living labs as a service design methodology. Next, we investigate a few preceding cases in Japan and Scandinavia for obtaining more detailed and in-depth knowledge about living labs. Based on this analysis, we clarify the methodological features of living labs such as processes, and similarities and differences among various methods. We then review the living lab methodology from the systems approach perspective, which is one of the well-known approaches to design products/services.

\section{Living Labs}

Living labs have been in varied contexts and processes in the last couple of decades. Table 1 shows the definitions of several living labs in previous work. The concept of living labs was first proposed in the United States in the 1990s by Lasher et al. (1991). This living lab was an experimental facility resembling a living environment, where researchers observed users trying new technology (Schuurman et al., 2015). Later, around 2005, the use of the term "living labs" was expanded in the Scandinavian countries. In this period, it became common to refer to living labs as a test bed for investigating and experimenting with new ICT services in the real-life settings and environment of the potential users. The definitions seen in this period are shown in the Table 1a (Følstad, 2008; Wood, 1997). As shown, the initial concept of living labs was to regard them as a test bed, where the user was considered a "subject and target for experiments". Later around 2010, living lab was often taken as "a place for co-creation with users" (Table 1b-d). In the most recent definition of living labs, which is similar to the authors' understanding, users are regarded as "partners that create a service together" rather than mere subjects or targets for experiments. In this way, living labs became a co- creation place or process for new services, where stakeholders including developers and users conducted innovation together.

Table 1. Definitions of Living Lab

\begin{tabular}{|c|c|c|}
\hline & Definition & Reference \\
\hline $\mathrm{a}$ & $\begin{array}{l}\text { Living labs are environments for innovation and development, where users are } \\
\text { exposed to new ICT solutions in (semi) realistic contexts, as part of medium- } \\
\text { or long-term studies targeting evaluation of new ICT solutions and discovery } \\
\text { of innovation opportunities. }\end{array}$ & (Følstad, 2008) \\
\hline b & $\begin{array}{l}\text { A living lab is a user-centric innovation milieu built on everyday practice and } \\
\text { research, with and approach that facilitates user influence in an open and } \\
\text { distributed innovation processes engaging all relevant partners in real-life } \\
\text { contexts, aiming to create sustainable values. }\end{array}$ & $\begin{array}{l}\text { (Bergvall-Kåreborn } \\
\text { et al., 2009) }\end{array}$ \\
\hline $\mathrm{c}$ & $\begin{array}{l}\text { Physical regions of virtual realities, or interaction spaces, in which } \\
\text { stakeholders from public-private-people partnerships (4Ps) of companies, } \\
\text { public agencies, universities, users, and other stakeholders, all collaborating } \\
\text { for creation, prototyping, validating and testing of new technologies, services, } \\
\text { products, and systems in real-life contexts. }\end{array}$ & $\begin{array}{l}\text { (Leminen and } \\
\text { Westerlund, 2012) }\end{array}$ \\
\hline d & $\begin{array}{l}\text { Living Labs (LLs) are defined as user-centred, open innovation ecosystems } \\
\text { based on a systematic user co-creation approach, } \\
\text { integrating research and innovation processes in real life communities and } \\
\text { settings. }\end{array}$ & (EC ENoLL, 2015) \\
\hline
\end{tabular}

\section{Investigation of Living Lab cases}

\subsection{Overview}

The literature survey described in Chapter 2 shows that the previous research introduced wide varieties of living lab concepts in depth, and cases studies, but not provided detailed description from the fields such as how to process living labs by the experienced practitioners. 
Therefore, in this research, to obtain detailed and in-depth hands-on information in practicing living labs, we investigated eight cases. In the investigation, we conducted field observation as well as depthinterview to practitioners (about 2 hours each). We applied semi-structured interview, in which interviewers constructed a list of basic questions in advance, and adjusted questions with flexibility on site based on answers and interactions with interviewees. The list of basic questions in the semistructured interview is shown in the Table 2.

Eight living lab cases investigated in this research include four Scandinavia cases (three Danish cases and one Swedish cases) and four Japanese cases. In this investigation, we intentionally chose cases, which are regarded as successful cases, and be possible to interview with the project owners. These conditions are critical to obtain practical as well as detailed experience based knowledge. In addition, we choose two different socio-cultural environments to identify similarities and differences beyond cultural bias. We then conduct literature reviews, field observations and/or interviews with representatives of the project (about two hours each). We label each case A to $\mathrm{H}$.

Table 2. A list of basic questions in the semi-structured interview

\begin{tabular}{|l|l|}
\hline Category & Basic questions \\
\hline $\begin{array}{l}\text { End-user/citizen } \\
\text { engagement }\end{array}$ & $\begin{array}{l}\text { - How do we engage end-users or citizens in service design process? } \\
\text { - How do we make the participation of citizens easy in design process? }\end{array}$ \\
\hline Consensus building & $\begin{array}{l}\text { - How do we build a consensus among stakeholders when selecting an idea in } \\
\text { participatory service design project? } \\
\text { - How do we persuade participants to lead them to a next action (namely, service } \\
\text { implementation and introduction)? }\end{array}$ \\
\hline $\begin{array}{l}\text { Design tools and } \\
\text { environment }\end{array}$ & $\begin{array}{l}\text { - What tools (workshop materials) are suitable to use for realizing proactive } \\
\text { engagement of end-users or citizens? } \\
\text { - What design environment (room, instrument, etc.) should we prepare to realize } \\
\text { proactive engagement of end-users or citizens? }\end{array}$ \\
\hline $\begin{array}{l}\text { Basics of living lab } \\
\text { approach }\end{array}$ & $\begin{array}{l}\text { - How do you design (plan) your living lab project (e.g., process)? } \\
\text { - How can we differentiate "living lab" from other approaches (eg., testbed, lean } \\
\text { startup, corporate accelerator program, etc.) ? }\end{array}$ \\
\hline
\end{tabular}

\subsubsection{Case A, Japan}

In this living lab, the lab members are senior citizens that test products provided by companies. The members verify the usability of services and tools, and give advice for improvement to the companies. In some cases, the members bring back a product to conduct verification at home.

\subsubsection{Case B, Japan}

This living lab was established in the rehabilitation division of a regional day care centre. The seniors who frequently visit the centre, develop and verify welfare equipment in the rehabilitation environment. Several companies, universities and research centres bring prototypes of the welfare equipment to the centre and the participating seniors help to improve the equipment.

\subsubsection{Case C, Japan}

This living lab was established in a regional private house. The private house was rented out to a small start-up company, which design and produce child care products for grandparents' generations. In the living lab, mothers, their small children and seniors work together for planning, designing and creating child care products especially targeted to senior child-care givers.

\subsubsection{Case D, Japan}

The members of this living lab consist of seniors, who live in the region. Seniors, companies, and municipalities collaborate to create ideas as well as verify and improve new products and services that the healthcare industry provides. 


\subsubsection{Case E, Denmark}

Initiated as a research project, a senior community, a university, a municipality, and an ICT company collaborate to design ICT services to solve local senior challenges. In this living lab, seniors are actively involved in problem identification, concept development, and test in a real living setting.

\subsubsection{Case F, Sweden}

In this living lab, immigrants, NGOs, a regional municipality, a university, and small and medium enterprises collaborate to create services for immigrants. From the initial stage of the project, immigrants are continuously involved in the process, and small social experiments using prototypes are conducted multiple times.

\subsubsection{Case G, Denmark}

This living lab consists of a physical space with real-life living places. Here medical doctors, nurses, and patients discuss better future healthcare facilities and services for a new hospital building. A 1:1 scale mock-up area is established in which the care settings are reproduced for testing and discussing future medical facilities and treatment processes (Figure 1). By utilizing this mock-up, designers, doctors, and other medical personnel perform scenarios of the new service. Through acting out in the scene, participants in the performance can reflect on the validity of the service as own experience, and provide practical improvements.

\subsubsection{Case H, Denmark}

A healthcare design consulting company establishes a living lab in one large space of the company. The living lab supports design of healthcare related services and products, involving companies, healthcare personnel, users/patients, and municipalities. The mock-up area reproduces a care facility environment and private senior houses and used as a test facility. The stakeholders can utilize the mock-up area to plan, create, and verify ideas and products.

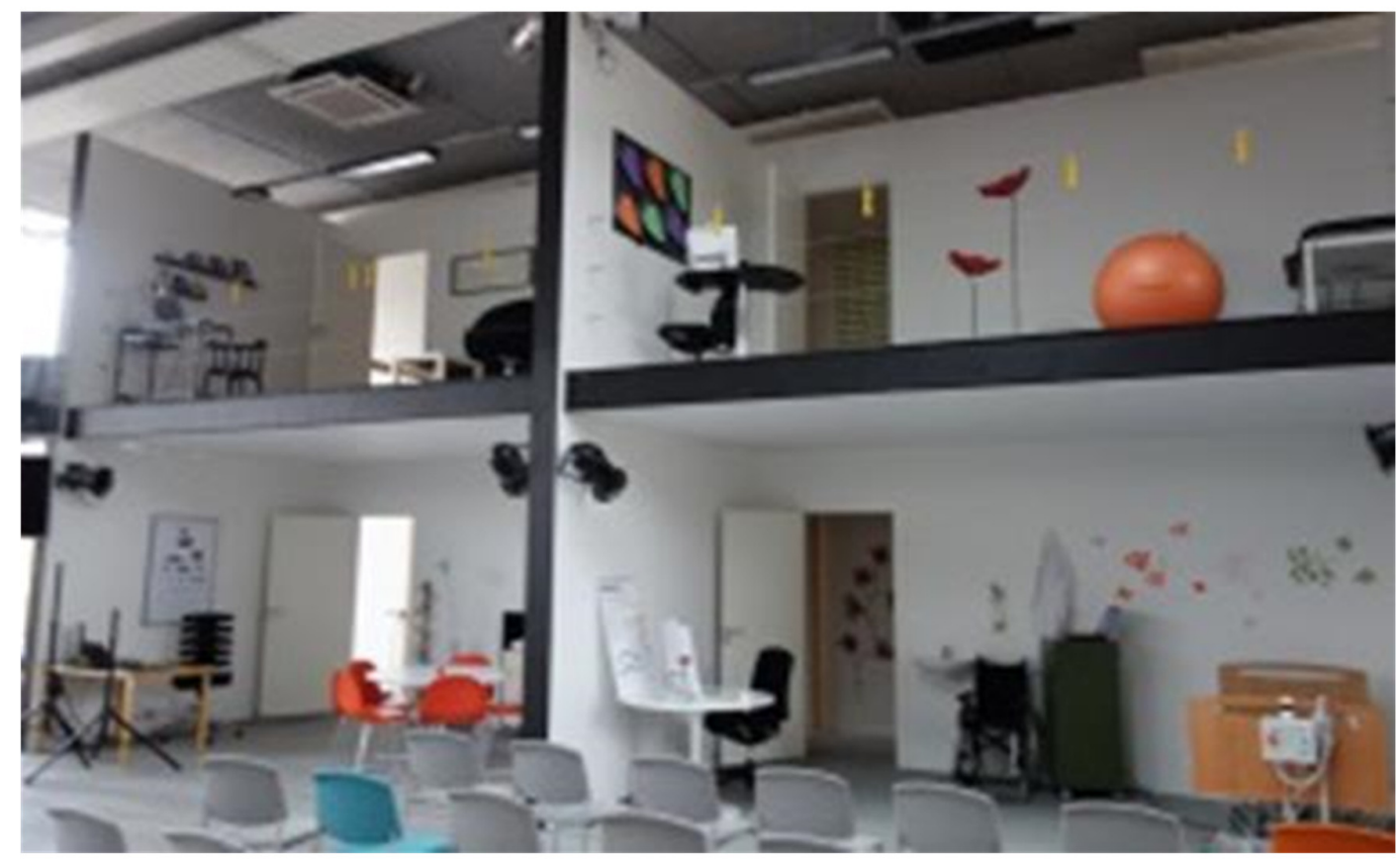

Figure 1. Mock-up Room 


\subsection{Case analysis}

By analysing interview data, through transcription, classification, and grouping key aspects, we identified the eight living labs can be classified in three viewpoints: (1) user relationships, (2) user roles, and (3) lab space. Table 3 shows the features of each case from the three perspectives.

\subsubsection{User relationships}

First, let us look at each case from a user involvement perspective. Case C, E, F, G, and H involve users already in the initial stages of the service creation. The involved participants find problems to solve by themselves in this early phase. In these cases, users are positively engaged in dialogue with other stakeholders. They build a shared problem understanding by discussing shortcomings, needs, and hopes. In case A, B, and D, a full-scale involvement of users starts in the verification phase after products and services have been materialized. These are similar to the test bed type of living labs.

\subsubsection{User roles}

Viewing the cases from a user roles perspective, case C, E, F, G, and $\mathrm{H}$ position users as partners in the overall design process. This indicates an expansion of the conventional user role. Case $\mathrm{C}$ is unique since the users are seniors that have a proactive central stake in the service creation. The other stakeholders such as designers and experts take supporting roles in the idea generation and development of services and products. In cases A, B, and D, although users only participate in the verification phase, their opinions and criticisms are highly valued. Moreover, users play an equal partner role in the service creation compared to their conventional verification role in a user test.

\subsubsection{Lab space}

Considering a lab space perspective, cases $\mathrm{G}$ and $\mathrm{H}$ provide a physical place such as a mock-up room that imitates the real-life space of the user. The user test and living lab process are conducted to the designated physical space. Other cases do not have any pre-defined experimental space. Instead, they utilize real living spaces as a lab space and conduct long-term user tests in these reallife settings.

\section{Living lab as methodology for service design}

In this section, we identify the methodological characteristics of living labs based on our analysis of the case studies. In particular, we focus on the design process of living labs and how it differs from conventional methods.

\subsection{Hypothesis search and hypothesis verification types}

From the case study, we found that living labs can be categorised into roughly two approaches. The first approach is used in cases such as C, E, F, G, and H. It involves users in the early design stages such as problem identification. In this paper, we call this living labs approach the "hypothesis-search approach". The second approach applies to case A, B, and D that involve users in verification and improvement of products that already are conceptualized and materialized. We call this living labs approach the "hypothesis verification approach". The hypothesis verification approach is often carried out as a closed process, involving only internal and related companies and designers in order to examine the concrete features of the service. Thus, considering it a service design methodology, this type of living labs approach is merely an extension of conventional service design and human centred design methods. On the other hand, the hypothesis search approach is an open-ended process that advances creation in collaboration with users from the early problem identification and idea creation phases. This is a new approach from the service design point of view. Therefore, in the rest of this paper, we focus on the hypothesis search approach, and clarify the methodological features of this living labs approach. 
Table 3. Comparison of varied living labs

\begin{tabular}{|c|c|c|c|c|}
\hline Case & "Living lab for..." & Levels of user involvement & User Role & Action Place/Space \\
\hline A & $\begin{array}{l}\text { Verification of tools } \\
\text { and services for and } \\
\text { by seniors. }\end{array}$ & $\begin{array}{l}\text { Close and in-depth involvement in } \\
\text { test and improvements. }\end{array}$ & Passive partner & $\begin{array}{l}\text { Users' private } \\
\text { home, University } \\
\text { labs. }\end{array}$ \\
\hline B & $\begin{array}{l}\text { Rehabilitation } \\
\text { support for seniors at } \\
\text { care centres. }\end{array}$ & $\begin{array}{l}\text { Close and in-depth involvement in } \\
\text { test and improvements. }\end{array}$ & Passive partner & $\begin{array}{l}\text { Rehabilitation } \\
\text { centre at day care. }\end{array}$ \\
\hline $\mathrm{C}$ & $\begin{array}{l}\text { Solution-oriented } \\
\text { service and tool } \\
\text { development for and } \\
\text { by seniors. }\end{array}$ & $\begin{array}{l}\text { End-users participate actively in } \\
\text { problem search, problem } \\
\text { identification, idea creation, concept } \\
\text { development, test, and } \\
\text { improvements. }\end{array}$ & Owner & $\begin{array}{l}\text { Community space, } \\
\text { where users } \\
\text { regularly gather, } \\
\text { and users' ordinary } \\
\text { daily private life. }\end{array}$ \\
\hline $\mathrm{D}$ & Senior's healthcare. & $\begin{array}{l}\text { Close and in-depth involvement in } \\
\text { test and improvements. }\end{array}$ & Passive partner & $\begin{array}{l}\text { users' ordinary } \\
\text { daily private life. }\end{array}$ \\
\hline $\mathrm{E}$ & $\begin{array}{l}\text { Developing ICT } \\
\text { support tools for and } \\
\text { by seniors }\end{array}$ & $\begin{array}{l}\text { End-users participate actively in } \\
\text { problem search, problem } \\
\text { identification, idea creation, concept } \\
\text { development, test, and } \\
\text { improvements. }\end{array}$ & Active partner & $\begin{array}{l}\text { users' ordinary } \\
\text { daily private life } \\
\text { on ICT use scene. }\end{array}$ \\
\hline $\mathrm{F}$ & $\begin{array}{l}\text { Developing social } \\
\text { services for and by } \\
\text { immigrants. }\end{array}$ & $\begin{array}{l}\text { End-users participate actively in } \\
\text { problem search, problem } \\
\text { identification, idea creation, concept } \\
\text { development, test, and } \\
\text { improvements. }\end{array}$ & Active partner & $\begin{array}{l}\text { users' ordinary } \\
\text { daily private life in } \\
\text { public space. }\end{array}$ \\
\hline G & $\begin{array}{l}\text { Developing } \\
\text { advanced hospital } \\
\text { related IT systems } \\
\text { and services for new } \\
\text { hospitals. }\end{array}$ & $\mathrm{E}$ & Active partner & $\begin{array}{l}\text { Mock-up room, } \\
\text { reproducing a care } \\
\text { environment }\end{array}$ \\
\hline $\mathrm{H}$ & $\begin{array}{l}\text { Developing } \\
\text { healthcare related } \\
\text { services. }\end{array}$ & $\begin{array}{l}\text { End-users participate actively in } \\
\text { problem search, problem } \\
\text { identification, idea creation, concept } \\
\text { development, test, and } \\
\text { improvements. }\end{array}$ & Active partner & $\begin{array}{l}\text { Mock-up room, } \\
\text { reproducing a use } \\
\text { environment, and } \\
\text { users' ordinary } \\
\text { daily private life at } \\
\text { home, care } \\
\text { institutions. }\end{array}$ \\
\hline
\end{tabular}

\subsection{Living labs process}

We summarize living labs process from the cases in the model depicted in Figure 2. As shown, living labs start with a dialogue among participating users, and/or between users and developers (designers and companies). The dialogue among stakeholders aims at sharing points of view such as; awareness of situations around problems such as regional social challenges, or subjectives opinions like dissatisfaction and hope. The ultimate purpose of this process is to build close human relationships between participants.

Next, the all stakeholders collaboratively look for challenges and define problems to be solved. In conventional service design, designers and companies often define challenges while in living labs, endusers also play a critical decision making role in this early design stage. Through involvement, the endusers will consider the challenges as their own challenges, and nourish their own inner motivations. It is important to foster consciousness about active participation and inner motivation among the endusers. This leads them to provide more constructive feedback in the service reviewing process. They might become active supporters as first users when the services and products are introduced into the market and society. 
Then the next step is to create ideas for solving the defined challenges (idea creation), and then to create prototypes that embody the idea (prototyping). Idea creation and prototyping require professional designers as well as engineers with in-depth knowledge and skills. It is of critical importance, however, to involve end-users as much as possible. The greater the involvement of the user is in this phase, the greater the awareness and motivation of the user will in the following phases. Next, the created prototype is verified in a real-life environment or similar environment (user test). Through the iterative process of idea generation, prototyping and user tests, a detailed service will form. By repeating verification in a real-life use settings, the service metamorphoses into a form that fits well with the user's real-life context of use.

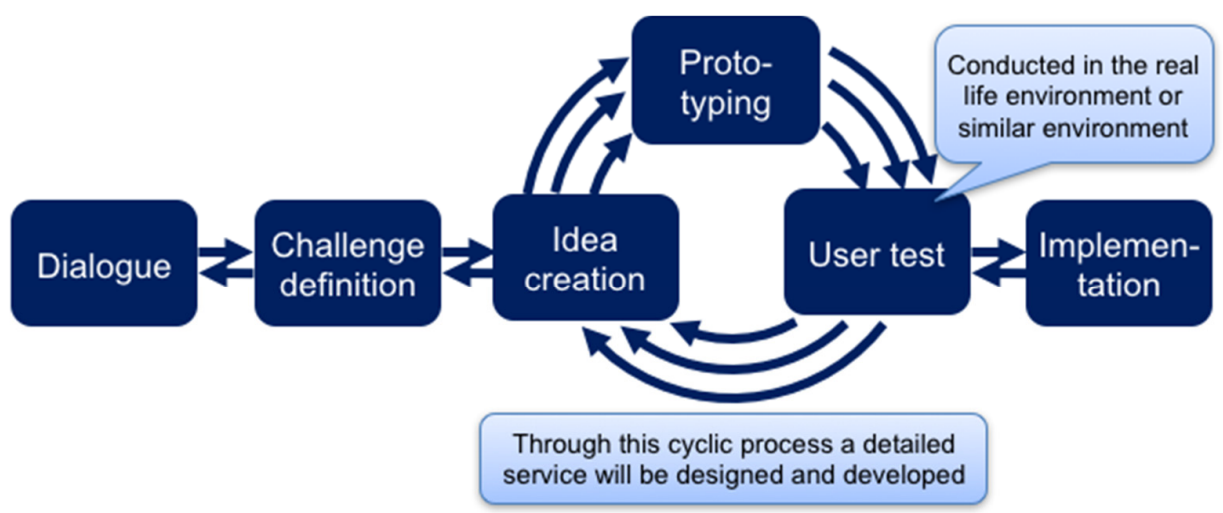

Figure 2. Living lab process

\subsection{Living lab as a learning process}

As mentioned in Section 4.2, living labs involve users continuously from the initial stage. There are largely speaking two benefits of this. The first benefit is an opportunity to create a highly aligned service to the users' real context of use. Through a living lab process, the service will positively incorporate the user's voice and adjust its interaction little by little over time before converging to a final form. The second benefit is a learning opportunity. Through the whole process of service development, the users continuously involve in the design process and decision-making (Figure 3). The users are involved in the design process from the initial stage of service creation, and by interacting and discussing with other users and stakeholders such as companies, they realize different viewpoints and new ideas from others and reflect on their own ideas and deepen their understanding of the challenges. By doing so, the users as well as other stakeholders can enrich their view of the situations. This is exactly the process of learning in community (Lave and Wenger, 1991), where participants will acquire their ownership mindset to the challenge by participation. Due to such an aspect of learning, the user can recognize their issues as their own challenge and feel ownership to the discussed ideas at a living lab. Such end-users often present more constructive opinions and new perspectives. Similarly, other stakeholders such as companies may also benefit from the dialogue with users in a living lab. By talking and discussing directly with the users, companies can touch upon the user's point of view or potentially realize that the company has wrong assumptions. This awareness towards undiscovered viewpoints are valuable assets for companies that can be utilized for service creation.

\subsection{Utilizing communities}

From our investigation, it became clear that future services often were discussed and studied within the pre-formulated user's community. In this context, the user's community indicates a group of people which share common interests and challenges and know each other to some extent. As such, they are different from temporary communities created for a single project. Such communities in living labs are probably equivalent to the third place for the user as Oldenburg defined as cosy cafes and bars, isolated from home and workplace (Oldenburg, 1999). The community is aware of common challenges and 
interests, and functions as a place to feel free to talk about each other's concerns. By developing services in such communities, our cases confirmed that users can share their honest feelings and opinions, and discuss constructively (e.g., cases A and C). Thus, we would like to point out that utilizing pre-created communities for developing services also is one of the noteworthy features of living labs.

\subsection{Summary of methodological features of living labs}

In Section 4.1, we introduced our view of living labs as hypothesis search approach types In Section 4.2, we identified key characteristics of living labs including seeing end-users as innovation partners as well as the importance of the iterative process of problem discovery, idea creation and prototyping in the real-life environment of the use scene. In the following Section 4.3 and 4.4, we considered living labs as places for learning and the utilization of pre-defined communities to create services. In sum, we have identified the following five methodological features of living labs from these cases:

1. A place to conduct a hypothesis search with users.

2. An approach that considers end-users as partners of service creation.

3. An experimental place to repeatedly verify and improve ideas (prototypes) in the real-life environment of users.

4. A place where stakeholders learn about problem situations and solutions.

5. An approach to utilize user communities to promote service creation.

Among these features, especially 1,4 , and 5 are never explicitly mentioned in the previous papers and works on living lab methodologies, and we argue that these new aspects are the core contribution of this research.

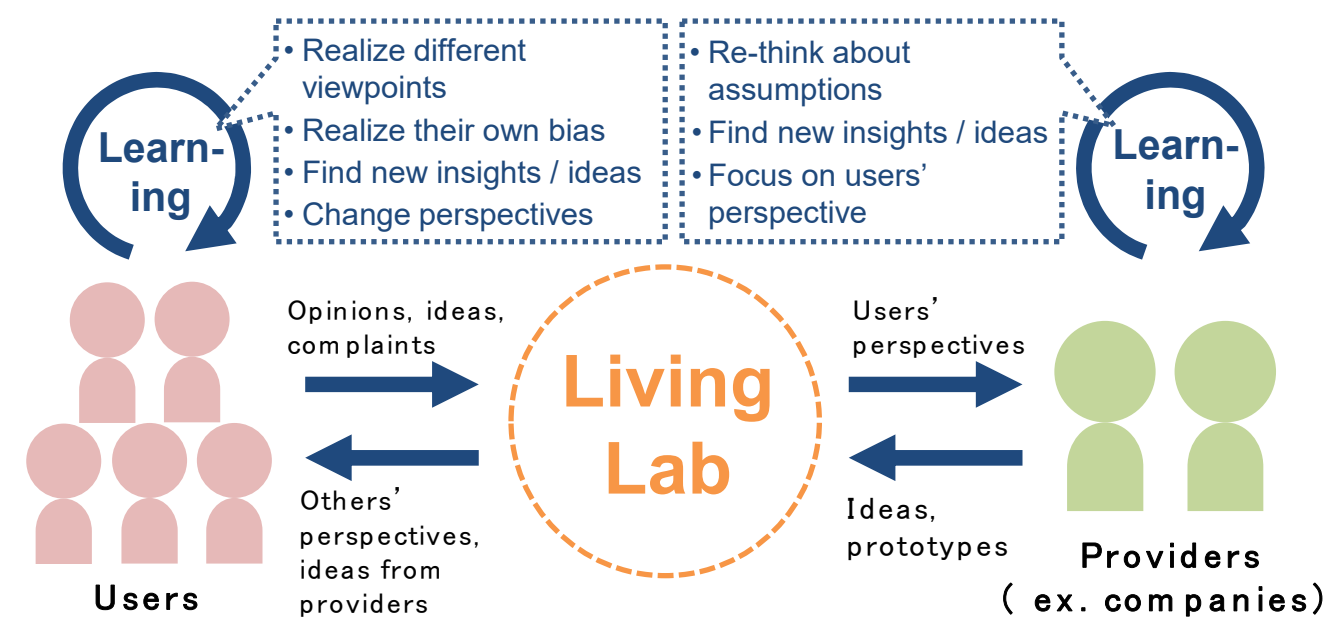

Figure 3. Living lab as learning process

\section{Thinking the features of living labs from the systems approach}

\subsection{Hard systems and soft systems}

In this section, we will re-examine living labs with the above mentioned features from the systems approach point of view. Since the systems approach is one of the well-known approaches to design products/services in design research community, it could be valuable to discuss methodological relationships between living lab and systems approach.

The systems approach is a problem solving approach that regards the target as a system that forms a holistic integral unit and eco-system based on multiple elements. The systems approach consists of the hard systems approach (HSA) and the soft systems approach (SSA) (Checkland and Scholes, 1990). HSA seeks for an optimal solution based on a systematic procedure through modeling and analyzing a complete process and structure for a well-defined problem. HSA assumes that the system can be modelled objectively and analysed and evaluated by a natural science method. Although HSA has 
achieved great success in the design of complex mechanical systems such as aircrafts, it has been pointed out that HSA is not effectively applicable to systems that involve humans such as social systems (Checkland and Scholes, 1990). When dealing with social systems, it is essential to handle feelings and subjectivity of human beings in society and other challenges that are not clearly definable.

SSA, on the other hand, was proposed in response to provide an answer to these limitations of HAS (Checkland, 1981). The soft systems methodology models subjective viewpoints describing how stakeholders perceive unstructured aspects of a problem situation. Then, based on this model, stakeholders conduct debate and find executable actions to solve the problem (Checkland and Scholes, 1990). Based on the premise that social complex problems cannot be described objectively, SSA structures a part of complicated problems by modelling the situation from the subjective viewpoint of the person in stake. For that reason, the model in SSA can be used only as a boundary object for debate. Through debate based on the model, stakeholders gradually start to share understandings of the problem, and establish accommodation, that is, a condition to challenge the problem together.

In this way, SSA can be understood as a methodology that explores solutions through acquiring new perspectives and ideas by utilizing tools such as models and debates, and at the same time, this forms the learning process itself.

\subsection{Living lab seen from the systems approach}

As mentioned earlier, living labs emphasize on problem identification through dialogue and the learning process of stakeholders. This indicates several similarities with SSA. However, unlike SSA that explores a problem space for problem solving, living labs examine concrete interactions of services and products. Not only models expressing stakeholders' subjectivity, but also models for describing the concrete features and systems of the service are required to process the living labs approach logically. A structural model for living labs is presumably close to the models used in HSA, and thus, it is important that living labs as a method for social challenges use both SSA and HSA models and methodologies as they are mutually complementary (Figure 4).

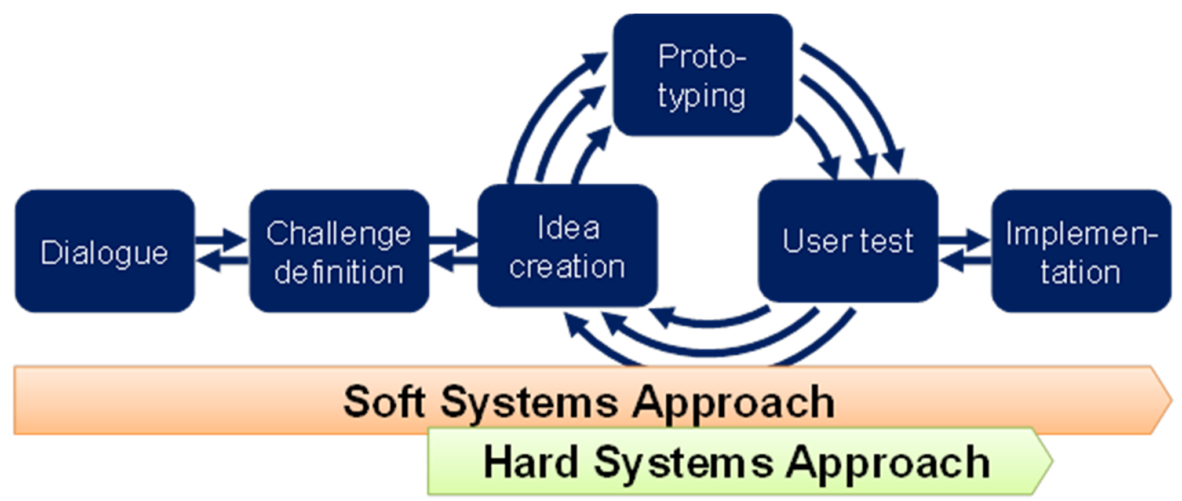

Figure 4. Systems approach and living lab process

\section{Conclusion}

This paper aimed to clarify the characteristics of living labs as a service design methodology approach based on literature reviews and investigation to living lab cases. In this paper, we first reviewed literature of previous studies on living labs and then investigated a few preceding cases in Japan and Scandinavia. As a result, we identified the process shown in Figure 2 and the five features such as:

1. A place to conduct a hypothesis search with users.

2. An approach that considers end-users as partners of service creation.

3. An experimental place to repeatedly verify and improve ideas (prototypes) in the real-life environment of users.

4. A place where stakeholders learn about problem situations and solutions.

5. An approach to utilize user communities to promote service creation. 
Among these features, especially 1,4 , and 5 are never explicitly mentioned in the previous papers and works on living lab methodologies, and we argue that these new aspects are the core contribution of this research. This new way to see living labs is valuable especially for practitioners and researchers who are planning to conduct service design through living lab approach.

Additionally, in the final section, we discussed the features of living lab approach from a systems approach point of view. Through the discussion, we clarified that living lab is a design method using both SSA and HSA models and methodologies as they are mutually complementary.

\section{References}

Almirall, E., Lee, M. and Wareham, J. (2012), "Mapping Living Labs in the Landscape of Innovation Methodologies", Technology Innovation Management Review, Vol. 2 No. 9, pp. 12-18.

Bergvall-Kåreborn, B., Holst, M. and Ståhlbröst, A. (2009) "Concept design with a living lab approach", Proceedings of the 42nd Annual Hawaii International Conference on System Sciences, HICSS. https://doi.org/10.1109/HICSS.2009.123

Binder, T., Brandt, E., Halse, J., Foverskov, M., Olander, S., and Yndigegn, S. (2011), "Living the (Codesign) Lab", Nordic Design Research Conference, pp. 1-10.

Checkland, P. (1981), Systems Thinking. Systems Practice, John Wiley \& Sons.

Checkland, P. and Scholes, J. (1990), Soft systems methodology in action, Wiley.

EC ENoLL (2015), European Network of Living Labs (ENoLL). [online] Openlivinglabs.eu. Available at: http://www.openlivinglabs.eu/ (accessed n.d.).

Følstad, A. (2008), "Living Labs for innovation and development of information and communication technology: a literature review", Electronic Journal of Organizational Virtualness, Vol. 10, pp. 99-131.

Kareborn, B.B. and Stahlbrost, A. (2009), "Living Lab: an open and citizen-centric approach for innovation", International Journal of Innovation and Regional Development, Vol. 1 No. 4, pp. 356-370. https://doi.org/10.1504/IJIRD.2009.022727

Lasher, D.R., Ives, B. and Jarvenpaa, S.L. (1991), "USAA-IBM Partnerships in Information Technology: Managing the Image Project", MIS Quarterly, Vol. 15 No. 4, pp. 551-565. https://doi.org/10.2307/249458

Lave, J. and Wenger, E. (1991), Situated learning: Legitimate peripheral participation, 1st ed., Series: Learning in Doing: Social, Cognitive and Computational Perspectives, Cambridge University Press.

Leminen, S. and Westerlund, M. (2012) “Towards innovation in Living Labs networks”, International Journal of Product Development, Vol. 17 No. 1/2, pp. 43-59. https://doi.org/10.1504/IJPD.2012.051161

Ogonowski, C., Ley, B., Hess, J., Wan, L., and Wulf, V. (2013), "Designing for the living room: long-term user involvement in a living lab", Proceedings of the CHI'13 SIGCHI Conference in Human Factors in Computing Systems, pp. 1539-1548. https://doi.org/10.1145/2470654.2466205

Oldenburg, R. (1999), The Great Good Place, 3rd ed., Marlow \& Company.

Schuurman, D., De Marez, L. and Ballon, P. (2015), "Living Labs: a systematic literature review", Open Living Lab Days 2015.

Stickdorn, M. and Schneider, J. (2012), This is Service Design Thinking: Basics, Tools, Cases, John Wiley \& Sons.

Wood, L.E. (1997), "Semi-Structured Interviewing for user-centered design”, Interactions, Vol. 4 No. 2 , pp. 48 61. https://doi.org/10.1145/245129.245134

Yasuoka, M. and Kamihira, T. (2016), "How participation is practiced? - Extension of Participatory Design Model”, The ServDes Conference 2016, pp. 279-291.

Dr. Fumiya Akasaka, Researcher

NTT Corporation, Service Evolution Labs

Hikarinooka 1-1, 224-0033 Yokosuka-shi, Japan

Email: akasaka.fumiya@lab.ntt.co.jp 